Old Dominion University

ODU Digital Commons

Civil \& Environmental Engineering Faculty

Publications

9-1985

Effect of Grain Characteristics on Liquefaction Potential-In Search of Standard Sand for Cyclic Strength

Isao Ishibashi

Follow this and additional works at: https://digitalcommons.odu.edu/cee_fac_pubs

Part of the Materials Science and Engineering Commons 


\author{
Isao Ishibashi ${ }^{1}$
}

\title{
Effect of Grain Characteristics on Liquefaction Potential - In Search of Standard Sand for Cyclic Strength
}

\begin{abstract}
REFERENCE: Ishibashi, I., "Effect of Grain Characteristies on Liquefaction Potential-In Search of Standard Sand for Cyclic Strength," Geotechnical Testing Journal, GTJODJ, Vol. 8, No. 3, Sept. 1985, pp. 137-139.
\end{abstract}

\begin{abstract}
Since the original Monterey 0 sand, which had been used for cyclic triaxial testing system calibration, is not available any more, the search for an alternative sand was started. In order to provide useful information for the above purpose, liquefaction potentials were evaluated for Monterey 0 and $0 / 30$ sands and for ASTM Test Method for Compressive Strength of Hydraulic Cement Mortars (Using 2-in. or 50-mm Cube) (C 109) Ottawa sands from various sources. The results clearly indicated that the liquefaction potential was very sensitive to slight changes in material properties (mean grain size, coefficient of uniformity, sphericity, and volume decrease potential)
\end{abstract}

KEYWORDS: liquefaction, sands, pore water pressures, cyclic strength

In 1976 Silver et al [1] compiled cyclic triaxial test results of the saturated Monterey 0 sand with a given density performed at eight different laboratories and presented a unique relationship between the cyclic strength and the number of cycles to liquefaction, which can be used as a calibration curve to assess the adequacy of their cyclic triaxial testing systems.

C. K. Chan at the University of California, Berkeley, then secured one hundred 45-kg (100-1b) bags of Monterey 0 sand for the system calibration purpose. In 1983, practically all of those 100 bags have been distributed out and none of them are available any more. The manufacturer of the sand, Lone Star Industries of Oakland, CA, stopped producing the Monterey 0 sand in 1977, and they substituted it with similar sands, namely, Monterey $0 / 30$ and $0 / 70$ sands.

Recently research has been conducted by Muzzy [2] to study the cyclic performance of the Monterey 0/30 sand in comparison with the old Monterey 0 sand. The Muzzy's result indicated that the Monterey 0 and $0 / 30$ sands were definitely different in cyclic strength.

In 1983, a task group (ASTM D18.09.02A by I. Ishibashi and D. A. Tiedemann) was established to evaluate the characteristics

\footnotetext{
${ }^{1}$ Associate professor, School of Civil and Environmental Engineering, Cornell University, Ithaca, NY 14853. Member of ASTM.
}

of the Monterey sands. The group also concluded that the Monterey 0 and $0 / 30$ sands were different.

Since then, questions have risen: (1) Can we still use the 1976 original calibration curve by selecting an alternative sand? or (2) Do we need a new sand and should we make a new calibration curve?

For the purpose of providing assistance in answering the above questions, this paper was prepared to demonstrate how sensitive the grain characteristics are to the liquefaction potential by using a pore-pressure generation model, which was developed earlier by the author and others [3-5].

\section{Pore-Water Pressure Generation Model}

The pore-pressure prediction model employed in this paper uses four parameters, which are believed to be the most influential material properties and a density condition on liquefaction: mean grain size $D_{50}$, coefficient of uniformity $C_{u}$, sphericity $\psi$, and volume decrease potential $\left(e-e_{\text {min }}\right)$. The normalized pore-pressure rise during the $N$ th uniform cyclic shear stress application is given by

$$
\begin{aligned}
\Delta U_{N}= & \Delta u_{N} / \sigma_{c}=\left(1-U_{N-1}\right)\left[C_{1} N /\left(N^{C_{2}}-C_{3}\right)\right]\left(\tau / \sigma_{N-1}^{\prime}\right)^{\alpha} \\
C_{1}= & K\left(D_{50}\right) \psi^{5.4}\left(e-e_{\min }\right)^{2.25} \\
& \times\left\{\left[10.66 /\left(C_{u}^{2}+2.07 C_{u}+1.1\right)\right]+74\right\} M \\
C_{2}= & 2.0 \\
C_{3}= & 0.5 \\
\alpha= & 5.6\left(e-e_{\min }\right)+1.0
\end{aligned}
$$

where $K\left(D_{50}\right)$ is a unique function of $D_{50}$ [5]. Since the original model was developed based on the liquefaction test results by using a torsional simple shear device with the wet vibratory specimen preparation technique, the constant $M$ that appeared in $\mathrm{Eq} 1 \mathrm{~b}$ was newly introduced in this study in order to make the model comparable with experimental results obtained by a different cyclic shear device with a different specimen preparation technique. 


\section{Evaluation of Monterey 0 and $0 / 30$ Sands}

Figure 1 shows the average annual gradations of the Monterey 0 and $0 / 30$ sands, which was provided by Lone Star Industries. It was also reported that the gradation might change on a daily basis. The figure indicates that the Monterey $0 / 30$ sand had significantly less amounts of fractions of the 425-, 300-, and 212- $\mu \mathrm{m}$ (No. 40, 50 , and 70 ) sieve passing.

The material properties and conditions reported in the Silver et al and Muzzy experiments are summarized in Table 1 . The value of sphericity was assumed to be 0.85 for all the cases by this author. It can be seen in the table that there are slight variations in $D_{50}, C_{t}$, $\psi$ but rather large changes in $e_{60}-e_{\text {min }}\left(e_{60}\right.$ is the void ratio for $60 \%$ of relative density.)

To use the model, the constant, $M$ in $\mathrm{Eq} 1 \mathrm{~b}$ was first chosen to fit the calculated values in the Silver et al experimental data. The same $M$ value and the corresponding $D_{50}, \psi, e_{60}-e_{\min }$ values shown in Table 1 were then used to calculate the stress ratio to cause the initial liquefaction with the number of applied uniform stress cycles. Figure 2 compares the calculated values and the experimental data. It can be seen that the model explains reasonably well the discrepancies obtained in three Monterey sands, although the experimental data for Monterey $0 / 30$ sand show a slightly lower resistance especially at a higher number of cycles.

\section{Evaluation of ASTM C 109 Ottawa Sand}

Example calculations were made to demonstrate the potential differences in cyclic strength for ASTM Test Method for Compressive Strength of Hydraulic Cement Mortars (Using 2-in. or 50-in.

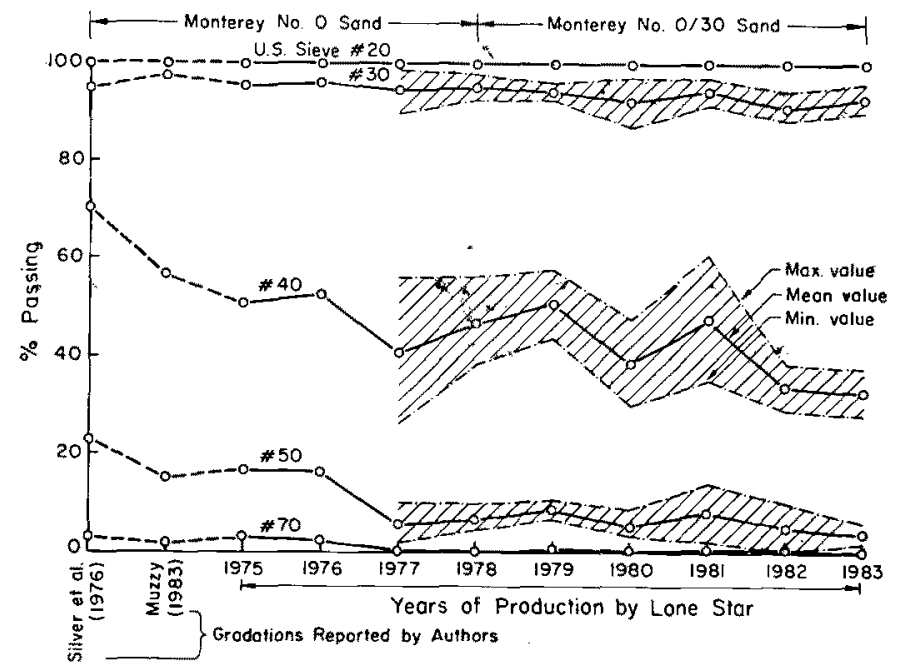

FIG. 1-Grain size distributions of Monterey 0 and $0 / 30$ sands.

TABLE 1-Properties of Monterey sands.

\begin{tabular}{llllllll}
\hline Sand Type & $G_{s}$ & $e_{\max }$ & $e_{\min }$ & $D_{50}$ & $C_{u}$ & $\psi$ & $e_{60}-e_{\min }$ \\
\hline No. 0[1] & 2.65 & 0.852 & 0.564 & 0.36 & 1.50 & $0.85^{a}$ & 0.115 \\
No. 0[2] & $2.65^{b}$ & $0.852^{b}$ & $0.564^{b}$ & 0.40 & 1.63 & $0.85^{a}$ & 0.115 \\
No. 0/30[2] & 2.65 & 0.803 & 0.563 & 0.45 & 1.60 & $0.85^{a}$ & 0.096 \\
\hline
\end{tabular}

${ }^{a}$ Chosen by this author.

${ }^{b}$ Values from Silver et al [ 1$]$.

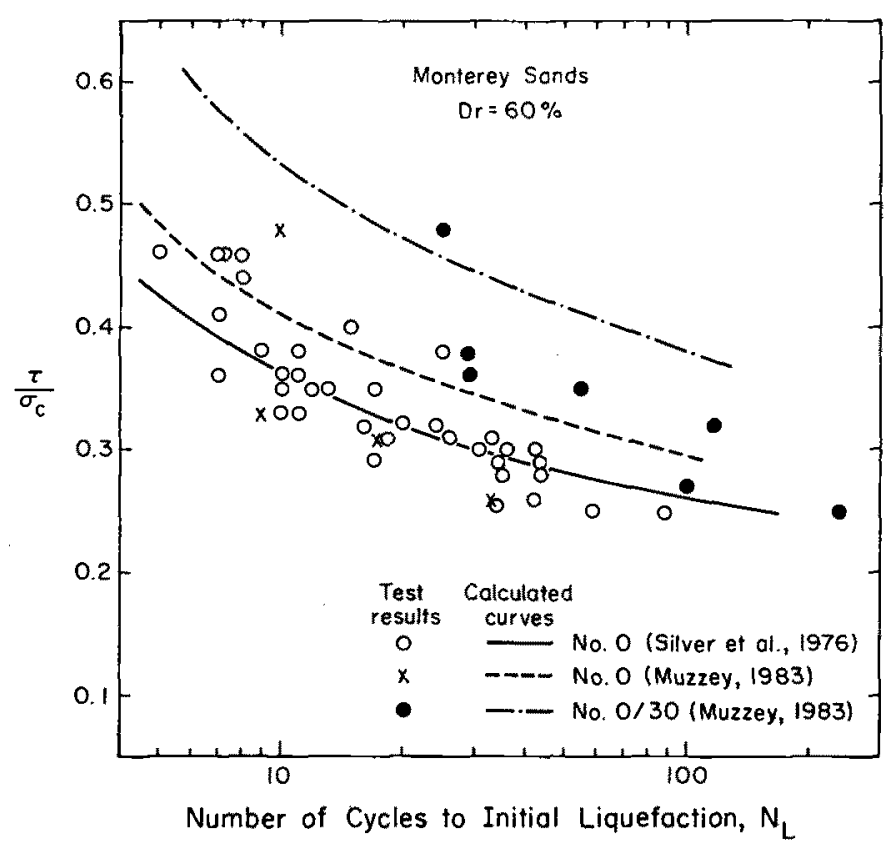

FIG. 2-Initiat liquefaction stress ratios for Monterey sands.

Cube) (C 109) Ottawa sand, which has also been used in cyclic shear experiments by many investigators.

ASTM C 109 Ottawa sand is a natural silica sand from Ottawa, IL, and should be graded as follows according to ASTM Specification for Standard Sand (C 778) (Table 2).

Four ASTM C 109 Ottawa sands were picked for this investigation as summarized in Table 3. University of British Columbia (UBC), University of Washington (UW) Syracuse University (SU), and Cornell University (CU) indicate the universities where Ottawa sands were used, and the numbers in the parentheses represent the years in which the sands were either obtained or used for liquefaction studies. The values for $G_{s}, e_{\min }, D_{50}$, and $C_{t}$ are nearly the same (but not exactly). A rather high $e_{\max }$ value of 0.82 was reported for $\mathrm{UBC}$ sand. The sphericity values for $\mathrm{UBC}, \mathrm{SU}$, and $\mathrm{CU}_{\mathrm{s}}$ sands were determined by a person during a short span of time using the Rittenhouse chart [5]. The $\psi$ value for UW sand was determined by another person asing Wadell's method [5].

Fictitious Sands A and B were created for a comparison purpose: Sand A has extreme values of $D_{50}, C_{w}, \psi$, and $e_{60}-e_{\min }$ among the values in Table 1 to represent the most possible liquefiable condition, and Sand B has the combination of parameters for the least liquefiable condition.

TABLE 2-Gtadations of Ottawa silica sand (ASTM C 109).

\begin{tabular}{lc}
\hline \multicolumn{1}{c}{ Sieve } & $\begin{array}{c}\text { Accumulative } \\
\text { Percentage } \\
\text { Retained }\end{array}$ \\
\hline No. $16(1.18 \mathrm{~mm})$ & none \\
No. $30(600 \mu \mathrm{m})$ & $2 \pm 2$ \\
No. $40(425 \mu \mathrm{m})$ & $30 \pm 5$ \\
No. $50(300 \mu \mathrm{m})$ & $75 \pm 5$ \\
No. $100(150 \mu \mathrm{m})$ & $98 \pm 2$ \\
\hline
\end{tabular}


TABLE 3-Properties of ASTM C 109 Ottawa sand.

\begin{tabular}{|c|c|c|c|c|c|c|c|}
\hline Sand Type & $G_{s}$ & $e_{\max }$ & $e_{\min }$ & $D_{s o}$ & $C_{u}$ & $\psi$ & $e_{60}-e_{\min }$ \\
\hline UBC (1972) & 2.67 & 0.82 & 0.50 & $\underline{0.42}$ & 1.90 & $0.812^{a}$ & 0.16 \\
\hline UW (1974) & 2.67 & 0.76 & 0.50 & 0.40 & $\overline{2.10}$ & $0.850^{b}$ & $\overline{0.13}$ \\
\hline SU (1982) & 2.66 & 0.78 & 0.48 & 0.38 & 2.20 & $\overline{0.806^{a}}$ & 0.15 \\
\hline CU (1983) & 2.65 & 0.76 & 0.50 & $\overline{0.40}$ & 2.13 & $0.754^{a}$ & 0.13 \\
\hline $\begin{array}{l}\text { A (most } \\
\text { liquefiable) } \\
\text { B (least }\end{array}$ & $\ldots$ & .. & & 0.38 & 1.90 & 0.850 & 0.16 \\
\hline liquefiable) & $\ldots$ & $\ldots$ & $\ldots$ & 0.42 & 2.20 & 0.754 & 0.13 \\
\hline
\end{tabular}

Note: UBC University of British Columbia, UW University of Washington, SU Syracuse University, and CU Cornell University.

aDetermined by a person using the Rittenhouse chart.

${ }^{b}$ Determined by the following equation based on magnified pictures of grains: sphericity $\psi=d_{c} / D_{c}$, where $d_{c}$ is the diameter of a circle equal in area to the projected area of the grain when the grain rests on one of its larger faces, and $D_{c}$ is the diameter of the smallest circle circumscribing the area of the above projected grain.

Stress ratios $\tau / \sigma_{c}$ to cause initial liquefaction were calculated for the above six different ASTM C 109 Ottawa sands and were normalized by the stress ratio of Sand $\mathrm{A}$ as shown in Fig. 3. The figure indicates that the liquefaction stress ratio could be varied as much as $200 \%$ even for the standard ASTM C 109 Ottawa sand, and it also demonstrates that slight variations in $D_{50}, C_{w}, \psi$, and $e-e_{\min }$ provide possibly a large change in liquefaction stress ratio.

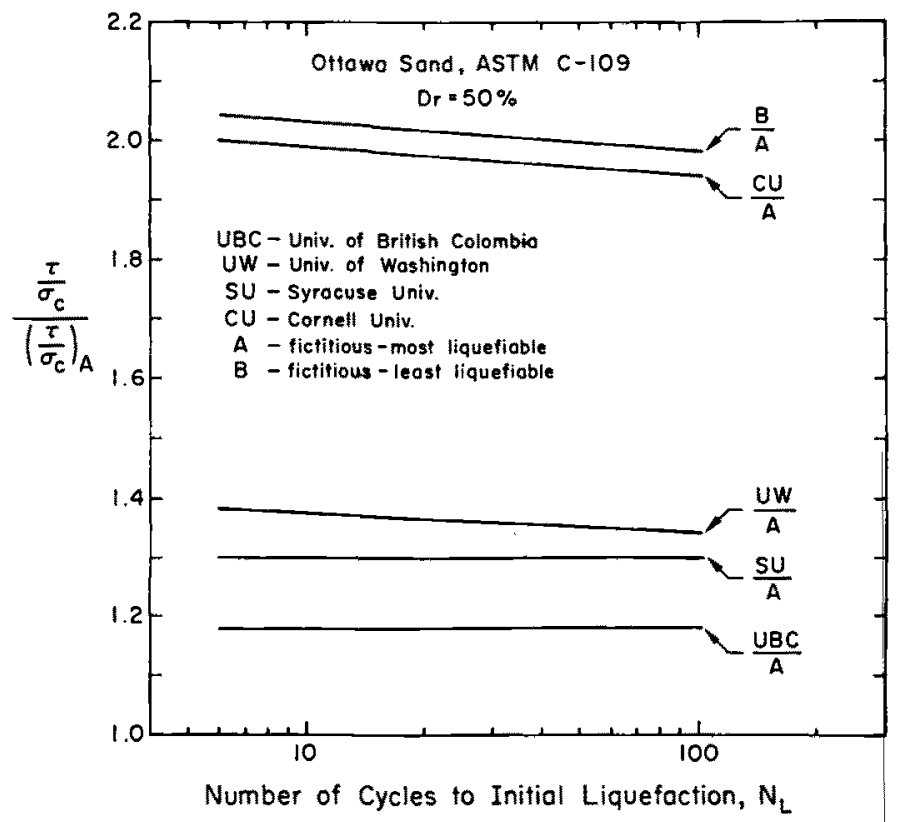

FIG. 3-Calculated initial liquefaction stress ratios for ASTM C 109 Ottawa sands with varying $\mathrm{D}_{50}, \mathrm{C}_{\mathrm{w}}$, and $\mathrm{e}-\mathrm{e}_{\text {min }}$.

\section{Conclusion}

Example calculations shown in this report for Monterey and Ottawa sands clearly show that the liquefaction potential is very sensitive to the slight changes in material properties and that it seems very difficult to have continuous supplies of a standard sand from commercial sources. Therefore it might be necessary again to secure a large quantity of a sand for the system calibration purpose. In such a case, it should be very cautious about making sure that all bags of the sand come from the same processing batch.

Even after securing a new standard sand and establishing a new calibration curve, however, we should be aware of the fact that many parameters other than soil type would significantly affect cyclic strength. Those are original grain structure (fabric), degree of saturation, wave form of cyclic stress, membrane penetration effect, and so forth. Among them, original fabric was reported to have a great effect on liquefaction, and it will easily be changed by the specimen preparation technique, previous vibration, age of deposit, initial anisotropic confining condition, and others. Therefore, a standard testing method should clearly identify the procedure to provide a consistent original fabric condition, and at the same time it should be mentioned that the adopted standard method does not necessarily provide a design cyclic strength in the field in order to avoid user's misuse.

\section{Acknowledgment}

The author is grateful to Professor S. K. Bhatia of Syracuse University for providing useful information about various Ottawa sands and for her valuable comments on this subject. The author would also like to thank Professor R. C. Chaney of Humboldt State University, the chairman of ASTM Subcommittee D18.09.02 on Cyclic Properties, for his encouragement in the preparation of this paper and his thorough review of the manuscript.

\section{References}

[1] Silver, M. L., Chan, C. K., Ladd, R. S., Lee, K. L., Tiedemann, D. A., Townsend, F. C., Valera, J. W., and Wilson, J. H., "Cyclic Triaxial Strength of a Standard Test Sand," Journal of Geotechnical Engineering Division, Proceedings of the American Society of Civil Engineers, Vol. 102, No. GT5, 1976, pp. 511-523.

[2] Muzzy, M. W., "Cyclic Triaxial Behavior of Monterey No. 0 and No. $0 / 30$ Sands," in partial fulfillment of the requirements for the Degree of Master of Science, Colorado State University, Fort Collins, CO, 1983.

[3] Ishibashi, I., Sherif, M. A., and Tsuchiya, C., "Pore-Pressure Rise Mechanism and Soil Liquefaction," Soils and Foundations, Vol. 17, No. 2, June 1977, pp. 17-27.

[4] Sherif, M. A., Ishibashi, I., and Tsuchiya, C., "Pore-Pressure Prediction During Earthquake Loadings," Soils and Foundations, Vol. 18, No. 4, Dec. 1978 , pp. 19-30.

[5] Ishibashi, I., Sherif, M. A., and Cheng, W. L., "The Effects of Soil Parameters on Pore-Pressure-Rise and Liquefaction Prediction," Soils and Foundations, Vol. 22, No. 1, Jan. 1982, pp. 39-48. 